\title{
On the morphological instability of silicon/silicon dioxide nanowires
}

F.M. Kolb • H. Hofmeister · M. Zacharias • U. Gösele

Published online: 11 July 2008

(C) Springer-Verlag 2008

Erratum to: Appl Phys A (2005) 80: 1405-1408

DOI 10.1007/s00339-004-3188-7

A typing error unfortunately lead to a wrong expression on page 1406 in the paragraph between equations (1) and (2). Instead of

$\lambda=\frac{2 \pi}{\kappa} \approx 4.5082 a$ it should read

$\lambda=\frac{2 \pi}{\kappa} \approx 4.508 \cdot 2 a$.

We thank Prof. Glaeser (University of California, Berkeley) for pointing out this error.

The online version of the original article can be found under doi:10.1007/s00339-004-3188-7.

F.M. Kolb $(\bowtie) \cdot$ H. Hofmeister · M. Zacharias · U. Gösele Max Planck Institute of Microstructure Physics, Halle, Germany e-mail: fkolb@mpi-halle.mpg.de 